\title{
Research Paper \\ Effect of Eight Weeks Plyometric Training on Some Kinematic Parameters, Hori- zontal Jumping Power, Agility, and Body Composition in Elite Parkour Athletes
}

\author{
*Abdolrasoul Daneshjoo ${ }^{1}$ (D), Soudabeh Raeisi² \\ 1. Department of Sport Biomechanics and Corrective Exercise, East Tehran Branch, Islamic Azad University, Tehran, Iran. \\ 2. Department of Sport Injuries and Corrective Exercise, East Tehran Branch, Islamic Azad University, Tehran, Iran.
}

\begin{tabular}{c|l}
$\begin{array}{c}\text { Use yourdevice to scan } \\
\text { and read the article online }\end{array}$ \\
Jumping Power, Agility, and Body Composition in Elite Parkour Athletes (Persian)]. Journal of Sport Biomechanics. 2020; \\
6(1):54-65. https://doi.org/10.32598/biomechanics.6.1.1 \\
doisths://doi.org/10.32598/biomechanics.6.1.1
\end{tabular}

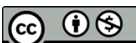

Article Info:

Received: 10 Mar 2020

Accepted: 15 May 2020

Available Online: 01 Jun 2020

Key words:

Plyometric exercise,

Agility, Kinematics,

Horizontal jump,

Parkour

\section{A B S TRACT}

Objective A high correlation between lower limb explosive power and muscular strength, production of high power levels in the shortest time, and high level of agility are essential to achieve optimal performance in Parkour. It seems that polymetric exercises can make it possible to achieve the highest performance. In this regard, the aim of the present study was to investigate the effect of an 8-week plyometric exercise program on knee kinematic parameters, body composition, agility and horizontal jumping power of Parkour athletes.

Methods In this quasi-experimental study with pre-test and post-test design, 20 elite Parkour athletes aged 19-26 years were selected and randomly divided into two groups of exercise $(n=10)$ and control $(n=10)$. The exercise group carried out the program for eight weeks, three sessions per week, each for one hour. Before and after exercise, measurements of kinematic parameters of knee, agility, and horizontal jumping power, and body composition in subjects were performed. The collected data were analyzed using t-test considering a significant level of $P \leq 0.05$.

Results Plyometric exercise for eight weeks had a significant effect on knee kinematic parameters of Parkour athletes $(P=0.003)$ and significantly improved their horizontal jump, agility and reduced body fat percentage $(P \leq 0.05)$.

Conclusion Plyometric exercise can significantly improve kinematic parameters of the knee, increase the jumping power and agility, and reduce body fat percentage in Parkour athletes; however, since Parkour movements are very similar to plyometric exercises, more study is needed.

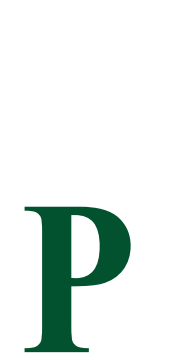

Extended Abstract

\section{Introduction}

arkour is an activity involving movement through obstacles in the fastest possible time using the easiest and simplest method with the least energy consumption from one point to other [1]. These plyomet- ric exercises enable the muscles to reach their maximum strength in the shortest possible time. They put a lot of pressure on the athlete's neuromuscular system and joints in a short period of time; if these exercises be performed without a proper and accurate program, they can cause severe damage to the joints and muscles [2].

Due to the high extrinsic contraction, which is a major component in plyometrics, Delayed Onset Muscle Sore-

\section{* Corresponding Author:}

Abdolrasoul Daneshjoo, PhD.

Address: Department of Sport Biomechanics and Corrective Exercise, East Tehran Branch, Islamic Azad University, Tehran, Iran.

Tel: +98 (21) 33585909

E-mail: phdanesh@yahoo.com 
ness (DOMS) is experienced steadily, especially in the early stages of pre-adaptation program. However, plyometric exercises have become commonplace and have always been an important element of exercise programs to increase an athlete's strength [2]. Other studies that have used plyometric exercises have also shown improvements in torque [3, 4]. The basis of parkour is jumping and running, and due to the ability of plyometric exercises to convert strength into explosive force, these exercises may be effective in parkour performance in [4]. This study aimed to examine the effects of an 8-week plyometric exercise program on kinematic parameters, body composition, agility and horizontal jump of elite parkour athletes in Tehran.

\section{Methods}

This is an applied quasi-experimental study using the field and laboratory tests. The study population consists of male parkour athletes in Tehran, Iran aged 19-26 years with at least 4 years of professional experience. Among the eligible volunteers, 20 who did not have any acute or chronic disease were selected as the study samples using G-Power software and were randomly assigned to training and control groups. Prior to the study, all subjects signed the consent form to participate in the tests and then, during a session, the subjects were explained how to perform the tests.

Kinematic parameters of the knee were measured using Navicular Drop Test, Tibial Torsion Test, Q-angle test, an-

Table 1. Comparing study variables before and after intervention in two study groups

\begin{tabular}{|c|c|c|c|c|c|c|c|c|}
\hline Variable & Time & Group & No. & Mean $\pm S D$ & Group & $\mathbf{t}$ & df & $\mathbf{P}$ \\
\hline \multirow{2}{*}{ Horizontal jumping power } & $\begin{array}{c}\text { Pre-test/post- } \\
\text { test }\end{array}$ & $\begin{array}{l}\text { Control } \\
\text { Exercise }\end{array}$ & $\begin{array}{l}10 \\
10\end{array}$ & $\begin{array}{l}254.5 \pm 12.34 \\
258.8 \pm 14.66\end{array}$ & Exercise & -4.498 & 9 & $0.001^{*}$ \\
\hline & $\begin{array}{c}\text { Pre-test/post- } \\
\text { test }\end{array}$ & $\begin{array}{l}\text { Control } \\
\text { Exercise }\end{array}$ & $\begin{array}{l}10 \\
10\end{array}$ & $\begin{array}{c}253.8 \pm 11.30 \\
262.3 \pm 13\end{array}$ & Control & 0.341 & 9 & 0.741 \\
\hline \multirow[b]{4}{*}{ Body fat percentage } & $\begin{array}{c}\text { Pre-test/post- } \\
\text { test }\end{array}$ & $\begin{array}{l}\text { Control } \\
\text { Exercise }\end{array}$ & $\begin{array}{l}10 \\
10\end{array}$ & $\begin{array}{l}16.35 \pm 1.51 \\
16.09 \pm 0.9\end{array}$ & Exercise & 3.186 & 9 & $0.011^{*}$ \\
\hline & $\begin{array}{c}\text { Pre-test/post- } \\
\text { test }\end{array}$ & $\begin{array}{l}\text { Control } \\
\text { Exercise }\end{array}$ & $\begin{array}{l}10 \\
10\end{array}$ & $\begin{array}{c}16.39 \pm 0.98 \\
15.7 \pm 0.62\end{array}$ & Control & -0.221 & 9 & 0830 \\
\hline & $\begin{array}{c}\text { Pre-test/post- } \\
\text { test }\end{array}$ & $\begin{array}{l}\text { Control } \\
\text { Exercise }\end{array}$ & 10 & $\begin{array}{l}12.67 \pm 4.22 \\
11.58 \pm 2.36\end{array}$ & Exercise & 2.277 & 9 & $0.049^{*}$ \\
\hline & $\begin{array}{c}\text { Pre-test/post- } \\
\text { test }\end{array}$ & $\begin{array}{l}\text { Control } \\
\text { Exercise }\end{array}$ & $\begin{array}{l}10 \\
10\end{array}$ & $\begin{array}{l}12.71 \pm 4.08 \\
11.09 \pm 1.86\end{array}$ & Control & -0.158 & 9 & 0.878 \\
\hline \multirow{2}{*}{ Body weight } & $\begin{array}{c}\text { Pre-test/post- } \\
\text { test }\end{array}$ & $\begin{array}{l}\text { Control } \\
\text { Exercise }\end{array}$ & $\begin{array}{l}10 \\
10\end{array}$ & $\begin{array}{l}69.37 \pm 8.73 \\
70.45 \pm 8.26\end{array}$ & Exercise & 1.288 & 9 & 0.230 \\
\hline & $\begin{array}{c}\text { Pre-test/post- } \\
\text { test }\end{array}$ & $\begin{array}{l}\text { Control } \\
\text { Exercise }\end{array}$ & $\begin{array}{l}10 \\
10\end{array}$ & $\begin{array}{l}69.65 \pm 8.39 \\
69.94 \pm 7.68\end{array}$ & Control & -0.624 & 9 & 0.548 \\
\hline \multirow[b]{2}{*}{$\mathrm{BMI}$} & $\begin{array}{c}\text { Pre-test/post- } \\
\text { test }\end{array}$ & $\begin{array}{l}\text { Control } \\
\text { Exercise }\end{array}$ & $\begin{array}{l}10 \\
10\end{array}$ & $\begin{array}{l}22.57 \pm 2.02 \\
22.35 \pm 1.66\end{array}$ & Exercise & 1.116 & 9 & 0.293 \\
\hline & $\begin{array}{c}\text { Pre-test/post- } \\
\text { test }\end{array}$ & $\begin{array}{l}\text { Control } \\
\text { Exercise }\end{array}$ & 10 & $\begin{array}{l}22.65 \pm 1.92 \\
22.38 \pm 1.58\end{array}$ & Control & -0.532 & 9 & 0.608 \\
\hline
\end{tabular}

$* \mathrm{P}<0.05$. 
teversion angle test, internal and external hip rotation, and knee hyperextension; body composition was analyzed with bioelectrical impedance IN-BODY 230 analyzer (InBody Inc., USA) in the pre-test and post-test stages; and the Illinois agility test was used to evaluate their agility. Then, plyometric exercises were performed.

\section{Results}

According to the normality of data related to horizontal jumping power, agility, body fat percentage, body weight and Body Mass Index (BMI), which was determined by Kolmogorov-Smirnov test, paired $t$ test was used to compare them. For comparing knee kinematic parameters, independent t-test was used. The results are presented in Table 1.

\section{Conclusion}

According to the sport of parkour, i.e. jumping through obstacles, the performance in parkour can exponentially be improved by increasing the jumping power. For this reason, the main goal of all exercises is to improve the jumping ability. Horizontal jumping power is measured by standing broad jump test and jumping is one of the main movements of parkour [5].according to Ozbar et al., Ramírez-Campillo et al., and Imani et al., plyometric exercises can increase strength and agility, and Parkour exercise makes horizontal jumping better and more powerful [6-8]. Concentric strength and stiffness of the biceps muscles in the back of the hip, which are hip extensor and knee flexor, can increase the rate of concentric contraction during hip extension and knee flexion. This function, combined with the high eccentric power of the knee extensors which prevents excessive flexion and center of mass fall, can increase vertical velocity and decrease horizontal velocity, which is desirable for a successful jump. In our study, the 8-week plyometric exercise program significantly reduced body fat percentage

Short limb length causes the pronation of the shortened limb. The difference in apparent length indicates the nonstructural difference between the two sides. One common cause of this discrepancy is the apparent short length of the hip adductor and abductor muscles in one side. The apparent difference in the length of the legs over time is due to the repetitive performance of regular activities. Work or exercise habits make one side of the spine stronger than the other.

\section{Ethical Considerations}

Compliance with ethical guidelines

All subjects voluntarily participated in this study and signed an informed consent form. They were assured that the principle of confidentiality would be observed in the preservation of the data and that all information obtained would be purely investigative and that they could withdraw from the research at any time (Code: IR.IAUETB.98073).

\section{Funding}

This article was extracted from a research project in the Department of Physical Education and Sports Sciences East Tehran Branch, Islamic Azad University.

\section{Authors' contributions}

Writing-editing: Abdolrasoul Daneshjoo; Implementation, data analysis: Soudabeh Raeisi.

\section{Conflicts of interest}

The authors declared no conflict of interest. 


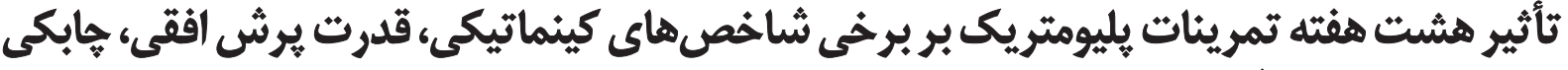 و تركيب بدنى ورزشكاران نخبه هاركور
}

\author{
(1) 'عبدالرسول دانشجو' (1)، سودابه رئيسى \\ 1. كروه بيومكانيك و حركات اصلاحى، واحد تهران شرق، دانشَّاه آزاد اسلامى، تهران، ايران.

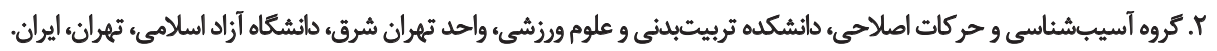

\begin{abstract}
حكيد

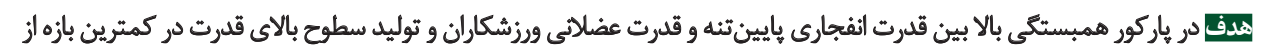

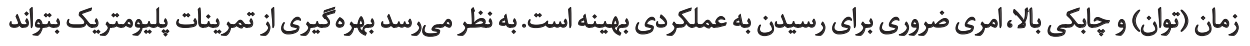

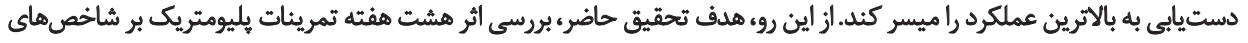

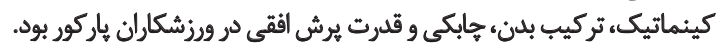

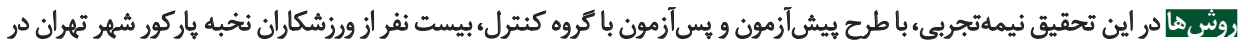

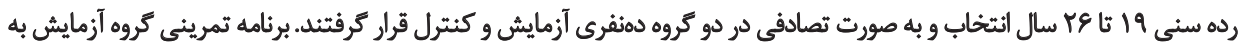

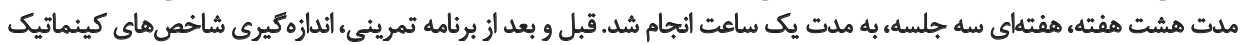

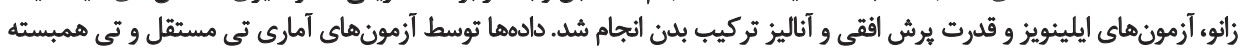
تانجزيه و تحليل شدند.

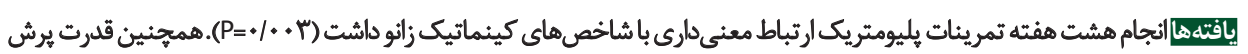

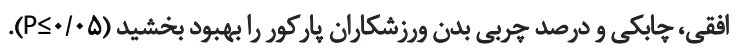

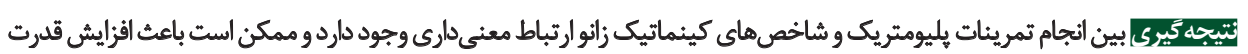

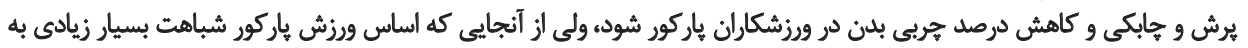

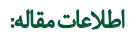

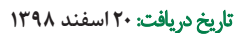

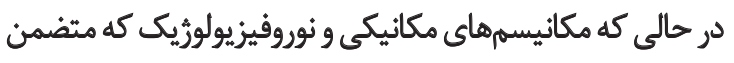

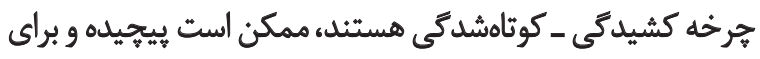

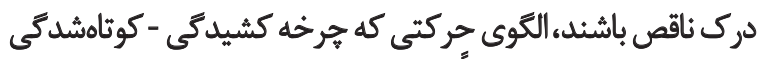

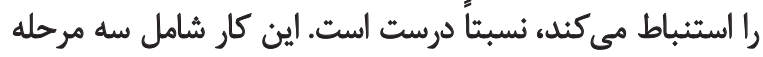

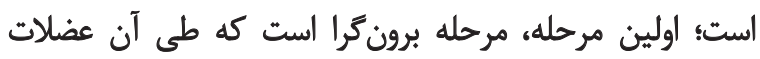

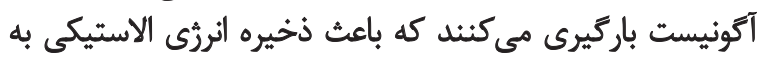

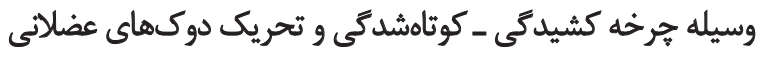

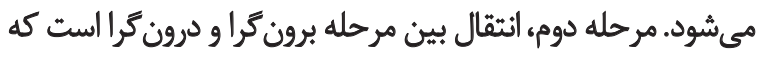

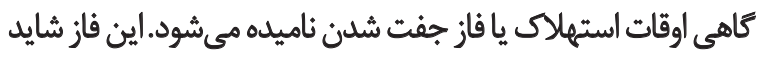

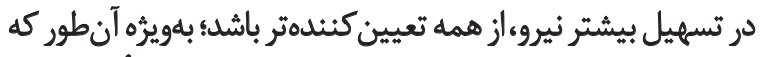

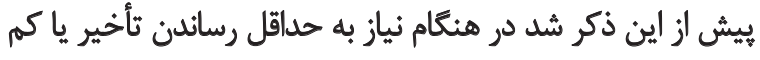

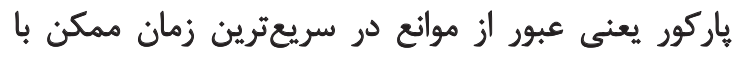

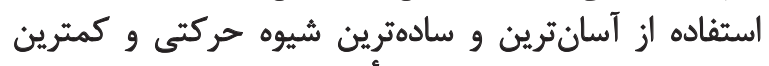

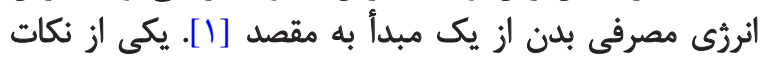

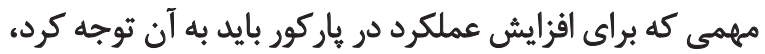

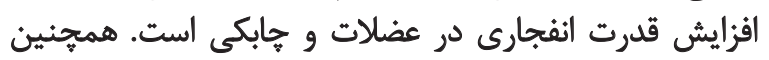

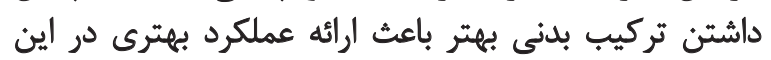

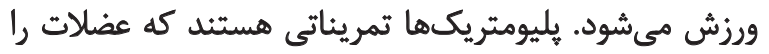

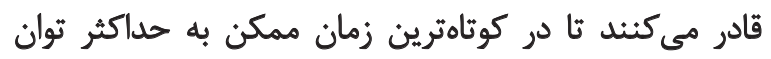

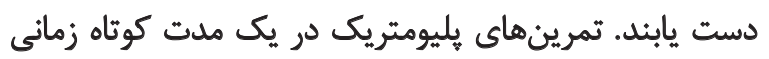

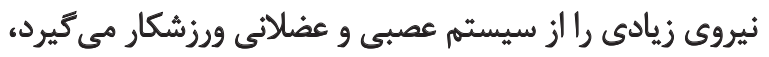

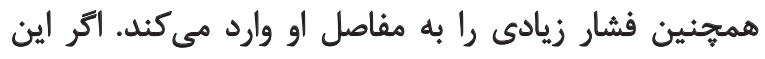




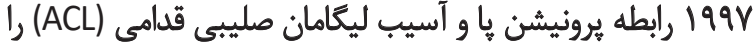

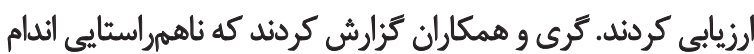

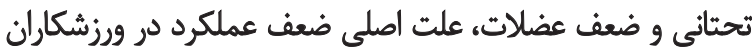

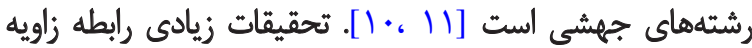

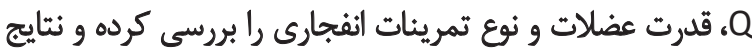

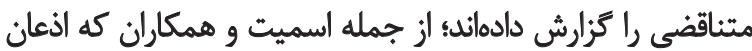

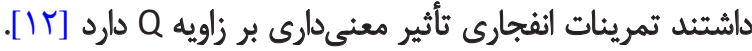

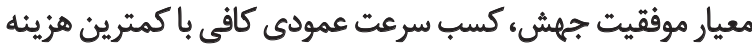

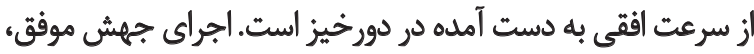

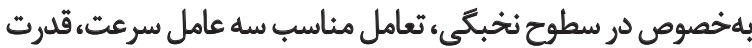

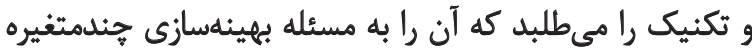

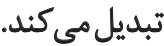

همان طور كه كفته شد با توجه به اينكه برش و دويدن اساس

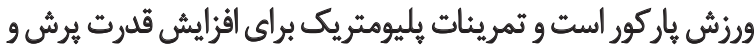

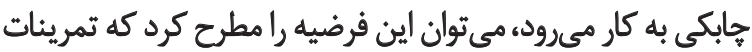

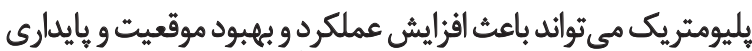

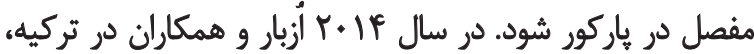

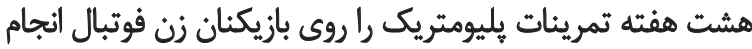

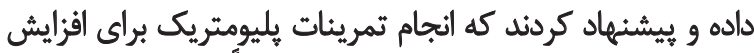

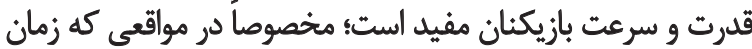

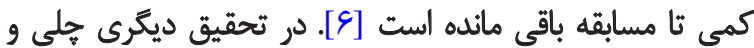

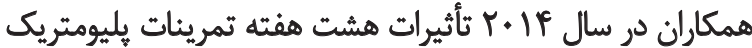

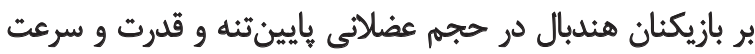

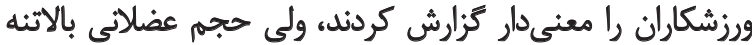

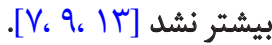

با توجه به اينكه هيج تحقيقى در زمينه تأثير تمرينات يليومتريك إني

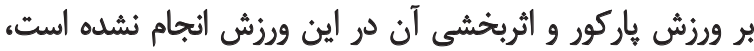

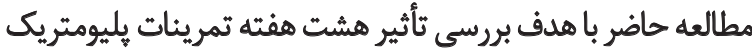

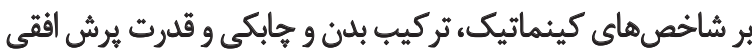
در باركوركاران نخبه تهران انجام شد.

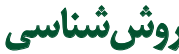

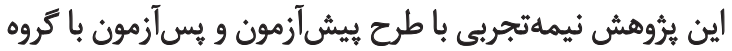

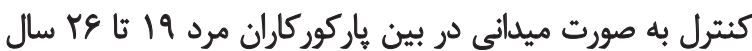

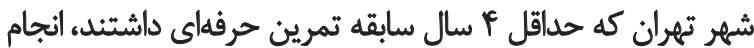

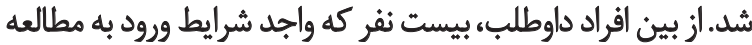

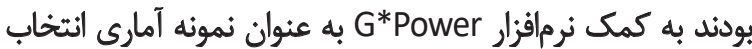

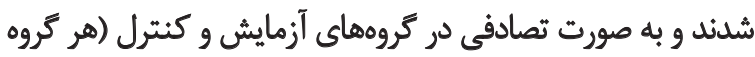

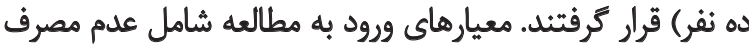

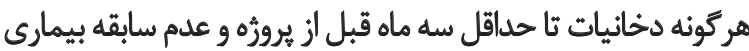

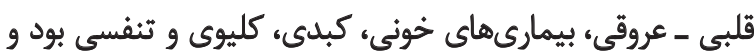

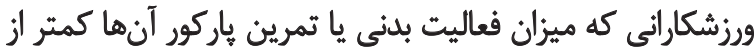

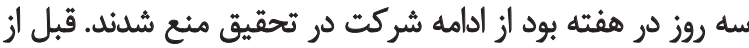

بودن زمان جفت شدن. فاز نهايي، فاز درون گراست كه طي آن اثرئى

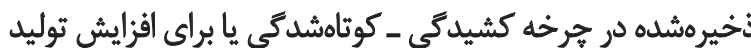

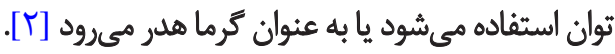

به عنوان نمونه اين تمرينات شامل فعاليتهاى برشى از جمله

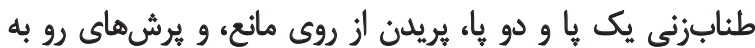

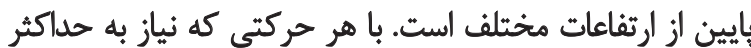

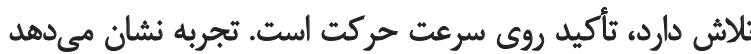

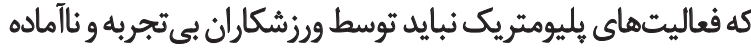

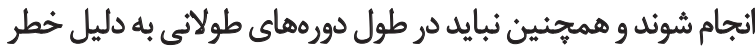

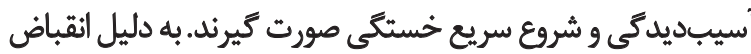

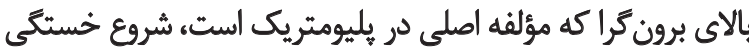

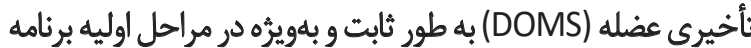

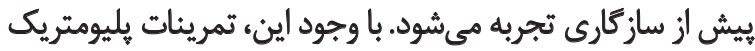

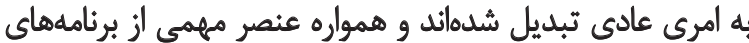
تمرينى براى افزايش توان ورزشكار هستئد.

كارايى اين تمرينات قابل ذكر نيست، اما توسط بثروهشهاى

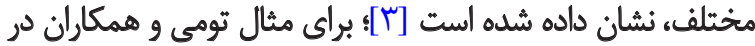

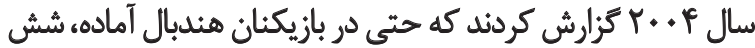

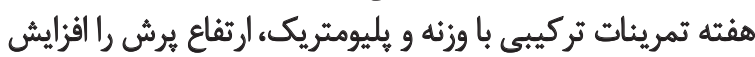

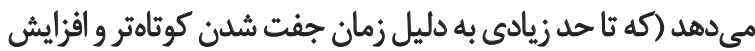

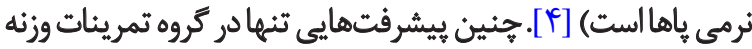

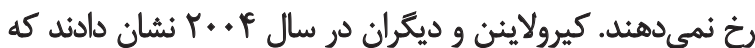

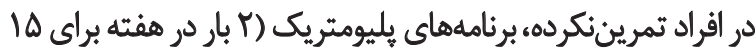

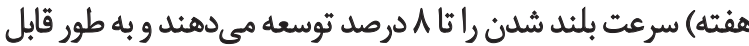

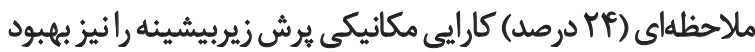

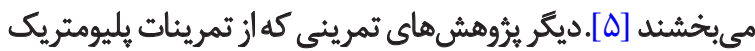

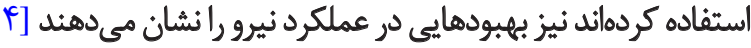

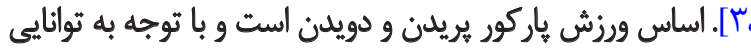

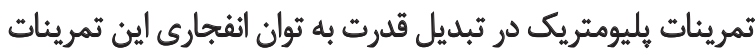

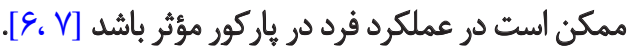

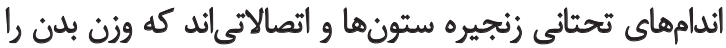

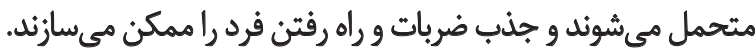

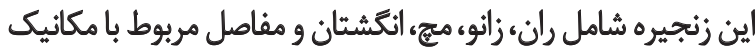

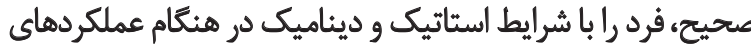

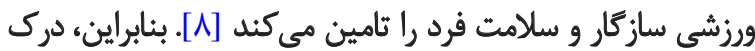

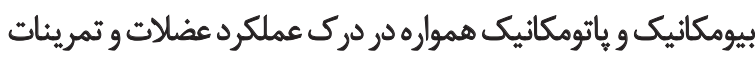

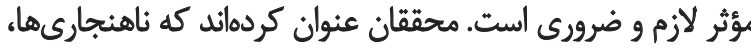

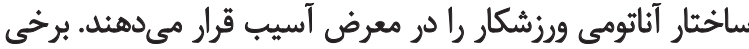

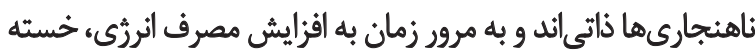

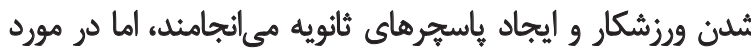

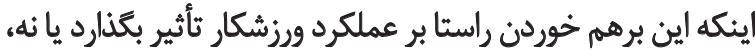

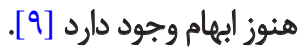

بكت و همكاران در سال 1997 و اسميت و همكاران در سال 


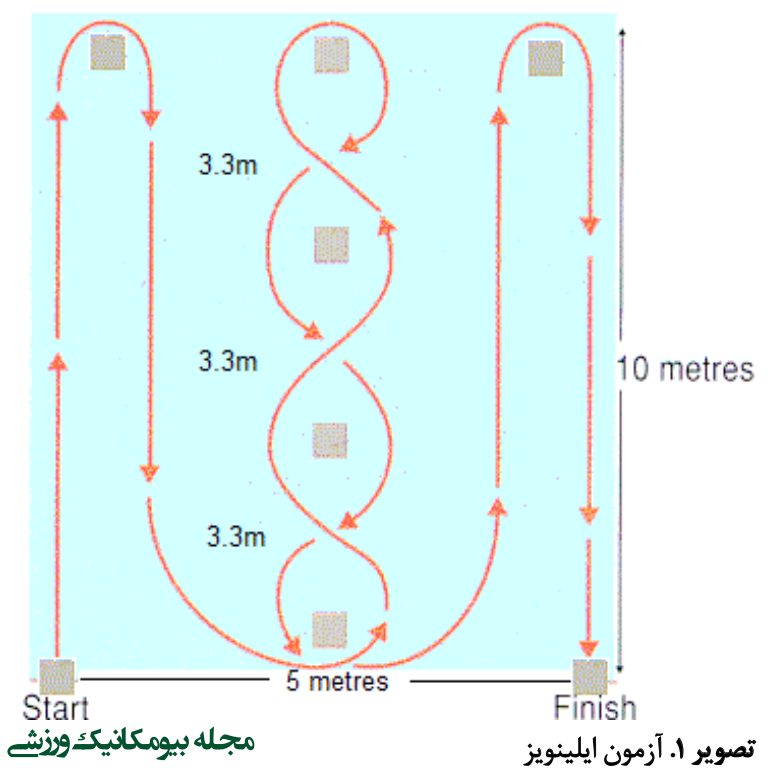

و خارجى ران و هايير اكستشن زانو به شرح زير انجام شد:

براي اندازمكيرى اندازه افت ناوى (تصوير r)، در حالى كه آزمودنى

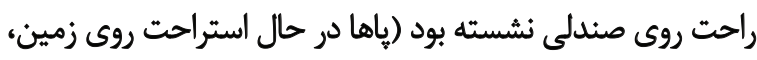

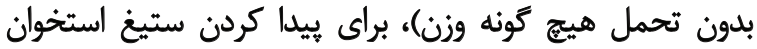

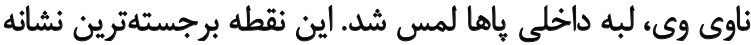

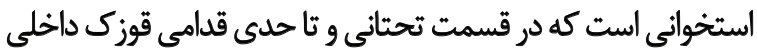

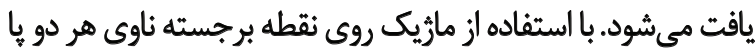

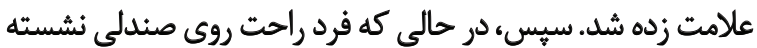

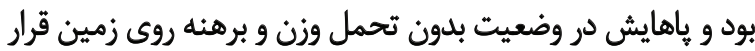

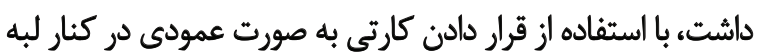

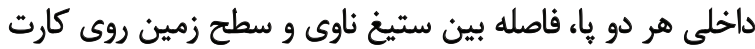

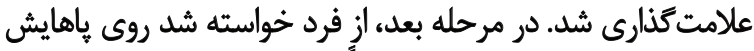

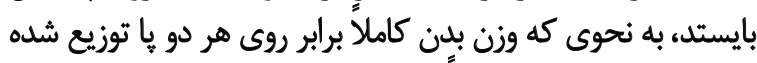

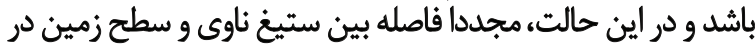

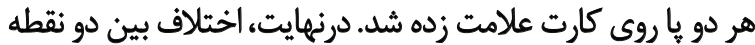

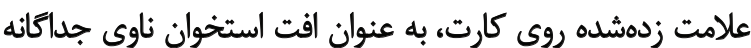

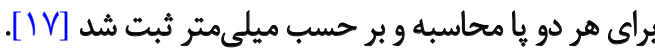

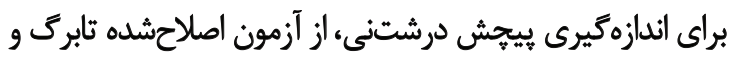

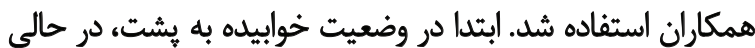

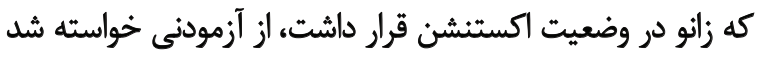

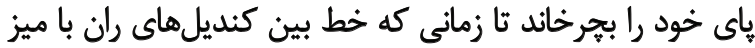

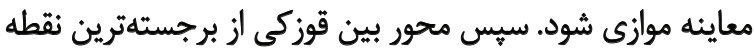

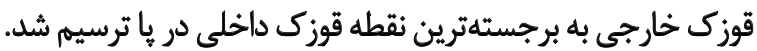

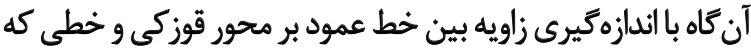

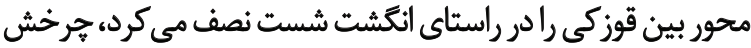

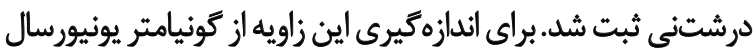

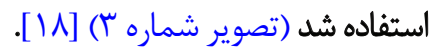

آغاز تحقيق، تمامى آزمودنىها فرم رضايتنامه شركت در آزمونهاى

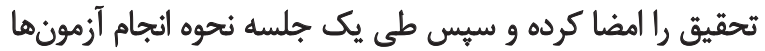

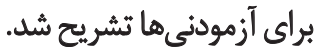

اندازهيرى شاخصهاى كينماتيك زانو و انجام تمريئات

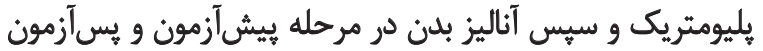

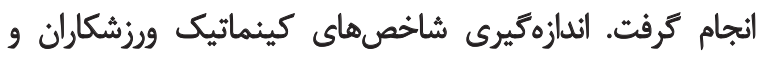

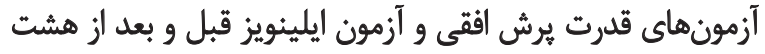
هفته تمرينات يليومتريك به شرح زير انجام شد:

به منظور اندازميرى تركيب بدن از دستكاه آناليز تركيب بدن

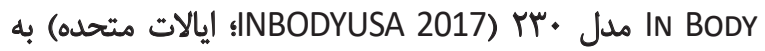
روش Bioelectrical Impedance استفاده شدء به اين صورت كه

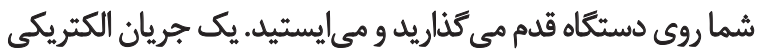

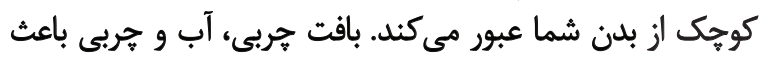

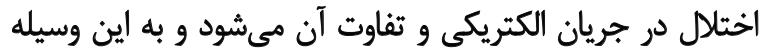

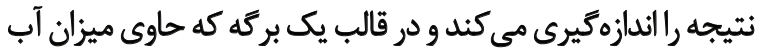

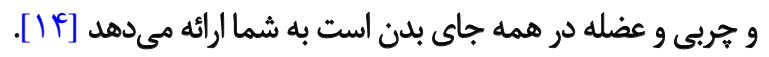
براى اندازهكيرى قدرت يرش افقى از آزمون يرش افقى به صورت إنات

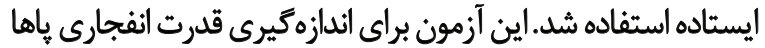

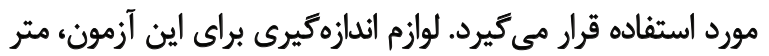

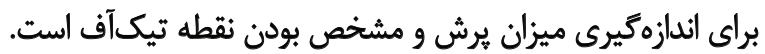

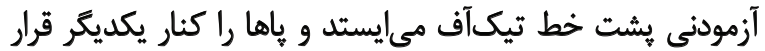

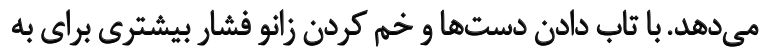

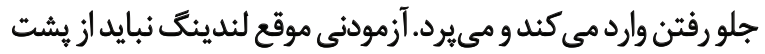

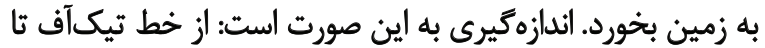

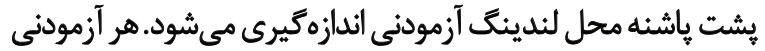

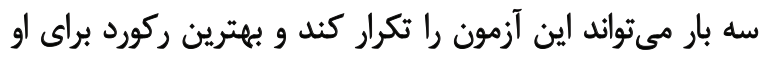

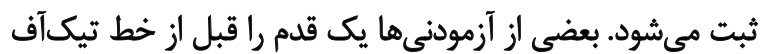

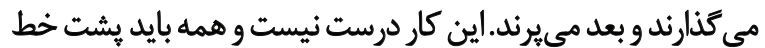

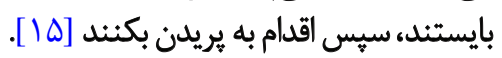

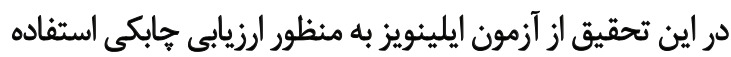

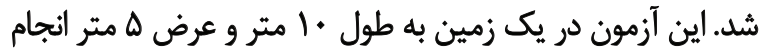

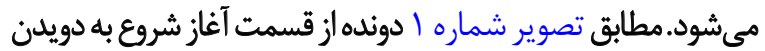

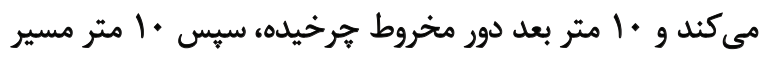

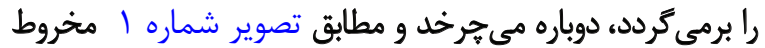

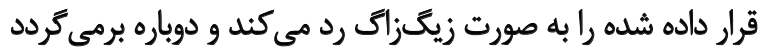

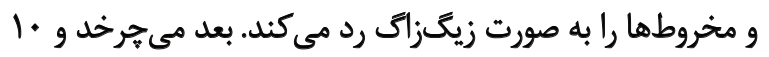

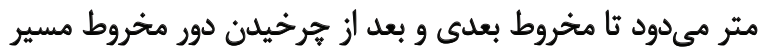

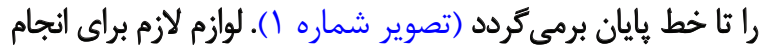

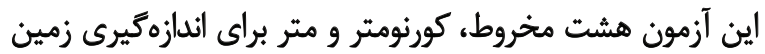

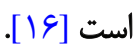

به منظور ارزيابى شاخصهاى كينماتيك زانو، آزمونهاى اندازه

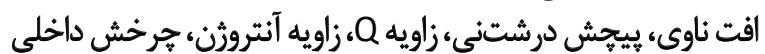




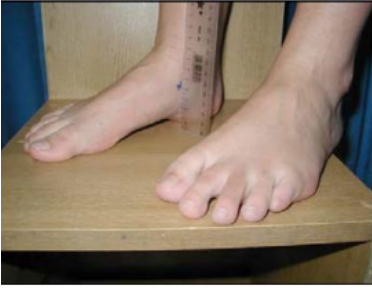

مجله بيومكانيك وزنش

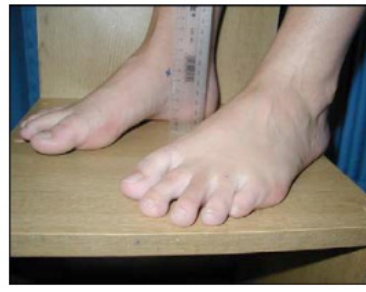

تصوير r. اندازهكيرى افت ناوى
كروه آزمايش به مدت هشت هفته تمرينات بليومتريك به صورت

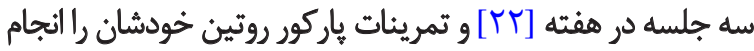

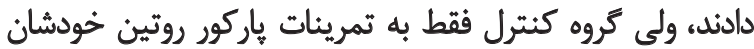

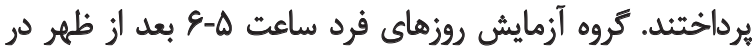

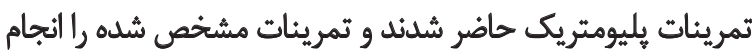

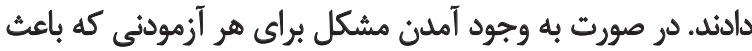

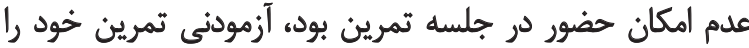

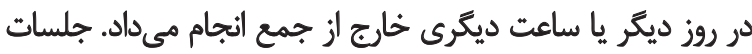

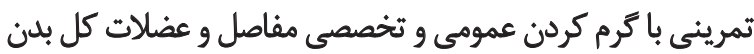

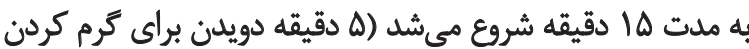

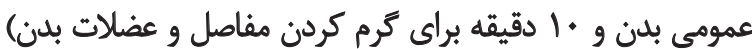

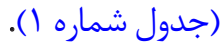

با توجه به اهميت استراحت بين ستها در تمرينات يليومتريك و

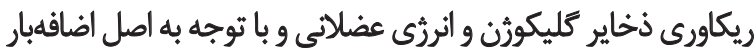

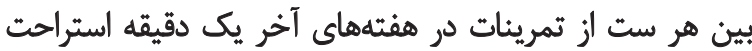

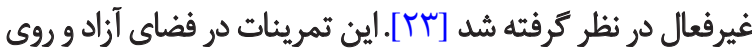

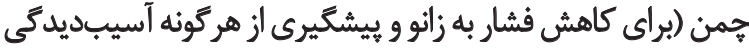

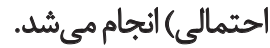

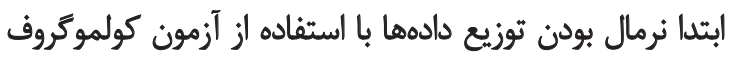

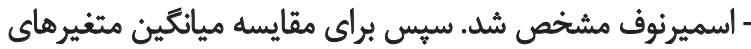

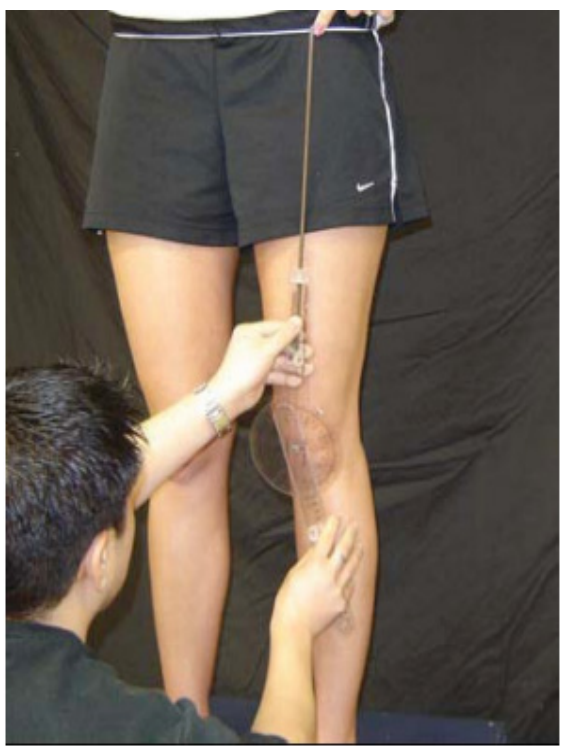

تصوير F. اندازهيرى زاويه Q در وضعيت ايستاده مجله بيومكانيك ولنش
زأويه Q در آزمودني ها در وضعيت ايستاده در حالي كه زانو و لكَن

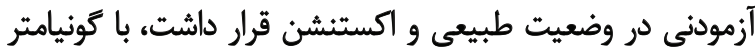

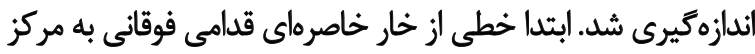

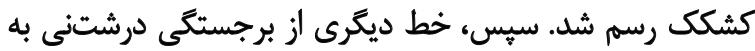
مركز كشكك ترسيم شد. سرانجام زاويهاى كه با اين دو خط دئ ايجاد

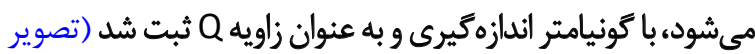

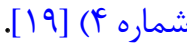

براى اندازهكيرى زاويه آنترورثن ران از تست كزيز استفاده شد.

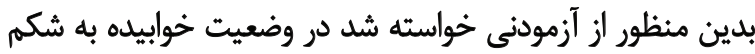

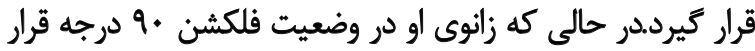

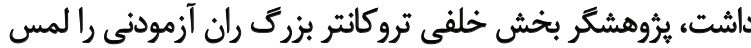

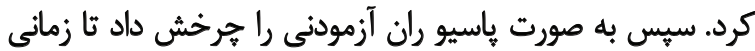

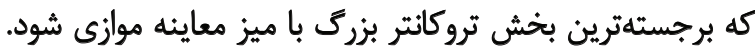

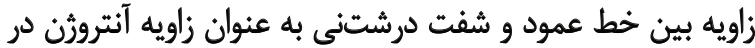

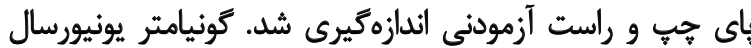

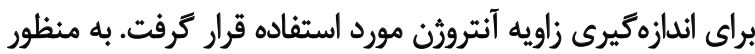

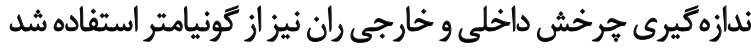

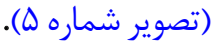

براى اندازهيرى حرخش خارجى از آزمودنى خواسته شد لبه

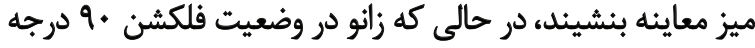

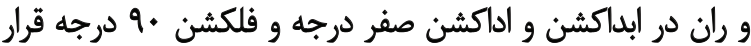

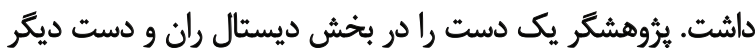

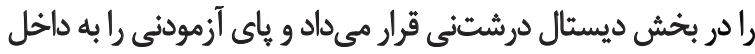

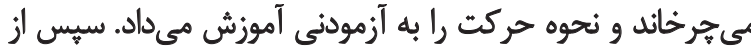

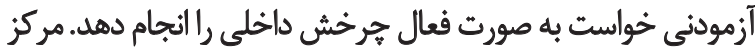

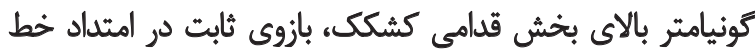

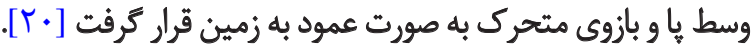

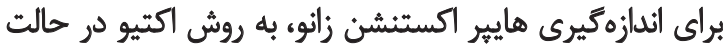

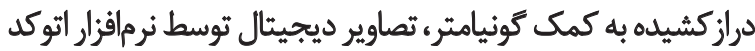

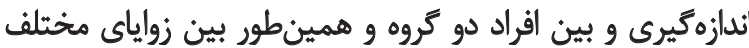

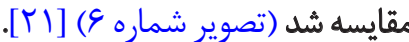

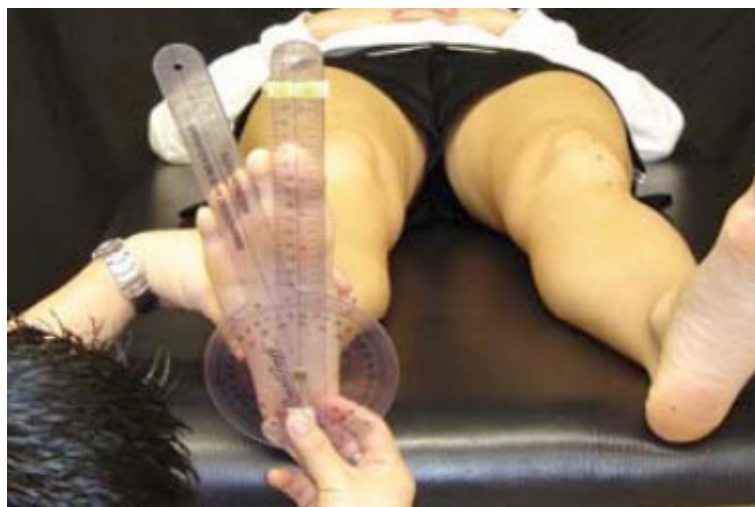

مجله بيومكانيك ورنش 


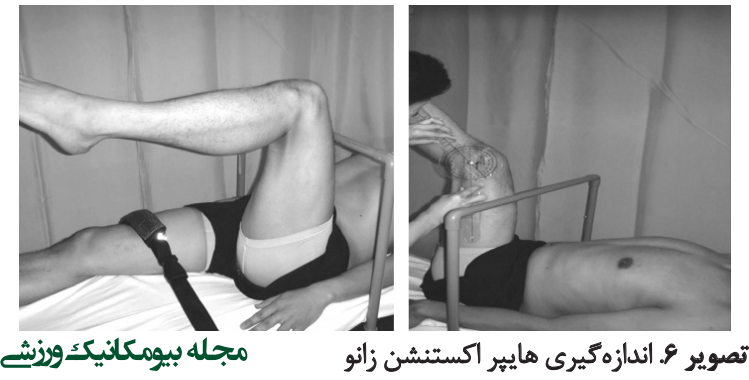

itis

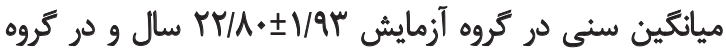

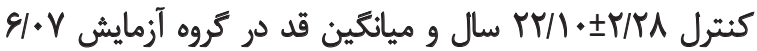

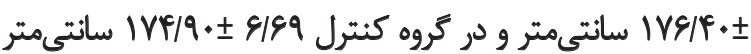

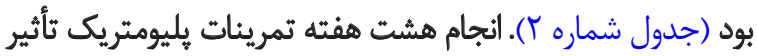

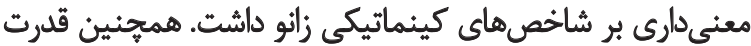

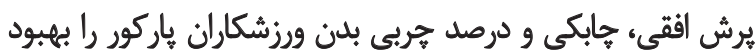

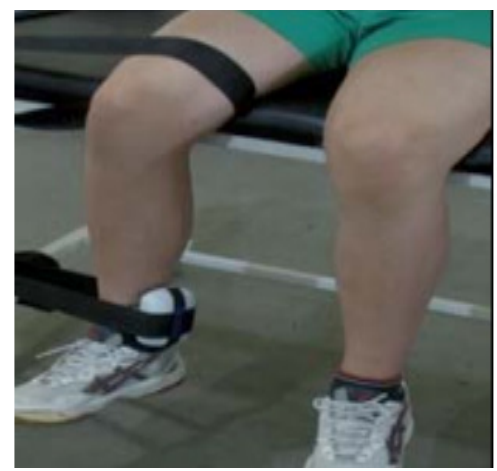

تصوير ه. آزمون جرخش داخلى وخارجى ران مجله بيومكانيك ونزش مربوط به قدرت يرش افقى، آزمون ايلينويز، درصد هربى بد بدن، وزئن

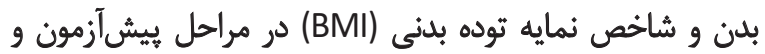

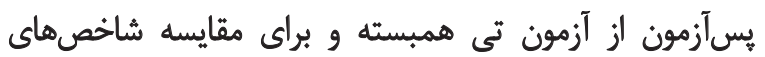
كينماتيك زانو از آزمون تى مستقل استفاده شد.

جدول أ. برنامه تمرينى آزمودنىهاي كروه آزمايش

\begin{tabular}{|c|c|c|c|c|c|c|c|c|}
\hline هفته هشتيم & هفته هفتم & هفته ششمي & هفته يُنجم & هنته هيهارم & هئه سوم & هفته دوم & هفته اول & تمرينات \\
\hline هات هـ & هـ ست & هـ ست & ها ست & f f & fأست & بست & rا ست & \multirow{4}{*}{$\begin{array}{c}\text { Vائو } \\
\text { (High knees) }\end{array}$} \\
\hline هز ثانيه & 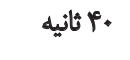 & هץ ثانيه & "ب ثانيه & ه" ثانيه & +" ثانيه & "ب ثائيه & ه ثانيه & \\
\hline . باثيه. & . عثائيه. & . ع ثائيه . & . جائيه & . مانيه & . & . الثانيه. & . أثائيه & \\
\hline استراحت & استراحت & استراحت & استراحت & استراحت & استراحت & استراحت & استراحت & \\
\hline هـ & هـ & هـ ست & ها هـ & لأبت & fأست & " ب ست & "است ست & \multirow{4}{*}{$\begin{array}{c}\text { السكوات يرشى } \\
\text { (Squat jumps) }\end{array}$} \\
\hline هب تكرار & •" بكرار & هץ تكرار & •r بتكرار & هT تكرار & r. risرار & rتكرار & ها تكرار & \\
\hline . ع ثانيه. & . ع ثانيه & . & و ه ثانيه & .9 ثانيه & و ثاثيه & . با ثانيه. & • اri ثائيه & \\
\hline استراحت & الستراحت & الستراحت & استراحت & استراحت & استراحت & الستراحت & استراحت & \\
\hline هـ & ها هـ & هـ ست & هات هت & f أست & ما ست & ب ست & r ست & \multirow{4}{*}{$\begin{array}{c}\text { بريك } \\
\text { (Burpees) }\end{array}$} \\
\hline هr تكرار & •rتكرار & ها تكرار & ماتكرار & ها تكرار & . اتكرار & . اتكرار & ه نكرار & \\
\hline . كثانيه. & . ع ثائيه & عاثئيه. & . & هو مانيه & . & . آثانيه. & . ثائيه IV. & \\
\hline استراحت & استراحت & استراحت & استراحت & استراحت & استراحت & استراحت & استراحت & \\
\hline ه ست & هـ ست & هـ ست & هـ ست & ff & fأست & "זست & r ست & \multirow{4}{*}{ 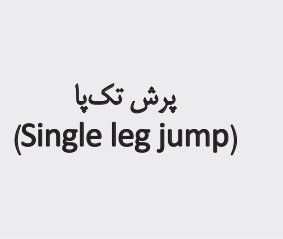 } \\
\hline . بتكرار & هr تكرار & •r تكرار & ها تكرار & . بتكرار & ها تكرار & ها تكرار & . اتكرار & \\
\hline . ع ثانيه & . 4 ثانيه. & . ع ثانيه & و ثانيه & و ثانيه & .9 ثاثيه & . rا ثانيه & . ا ا ثائيه & \\
\hline استراحت & استراحت & استراحت & استراحت & استراحت & استراحت & استراحت & استراحت & \\
\hline هـ ست & هـ ست & هـ ست & هـ ست & لم ست & f است & "r ست & "است & \multirow{4}{*}{$\begin{array}{c}\text { يرش اسكيتى } \\
\text { (Skater hops) }\end{array}$} \\
\hline هT تكراء & . تكرار & ها تكراء & ا تكرار & ها تكرار & ا تثكرار. & . اتكرار. & ه نتكرار & \\
\hline ع ثانيه & . ك ثائيه. & . & . 9 ثاثيه & 9 جانيه & . & . الثانيه & . & \\
\hline استراحت & استراحت & الستراحت & استراحت & استراحت & أستراحت & استراحت & استراحت & \\
\hline
\end{tabular}


جدول r. آمار توصيفى شاخصهاى آنترويومتريك دو كروه (هر گروه . ( نفر)

\begin{tabular}{|c|c|c|c|}
\hline ميانكين 土|نحراف أسئاندارود & 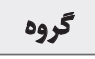 & مرحله & ثاخصهام \\
\hline$M Y / \pm T / Y A$ & كثترل & \multirow{2}{*}{\multicolumn{2}{|c|}{ سن (سال) }} \\
\hline$\pi / A \cdot \pm 1 / q \pi$ & آزمايش & & \\
\hline $\mid V f / 9+ \pm s / 89$ & كنترل & \multirow{2}{*}{\multicolumn{2}{|c|}{ قد (سانتىمتر) }} \\
\hline$|V \varepsilon / \varphi \cdot \pm q| \cdot \gamma$ & أزمايش & & \\
\hline$E q / T V \pm N N$ & كنترل & \multirow{2}{*}{ ييش آزمون } & \multirow{4}{*}{ ونين (كيلوكرم) } \\
\hline$V \cdot / P \Delta \pm N T E$ & آزمايش & & \\
\hline Eq/PDENTq & 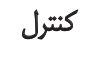 & \multirow{2}{*}{ يس أزمون } & \\
\hline sq/af $\pm V / 81$ & آزمايش & & \\
\hline$r Y / \Delta V \pm Y / . r$ & كنترل & \multirow{2}{*}{ ييشآزمون } & \multirow{4}{*}{ (كيلوكرم بر مترمربع) } \\
\hline MT/OHEI/Ee & أزهايش & & \\
\hline rr/Fati/ar & كتثرل & \multirow{2}{*}{ بسأزمون } & \\
\hline$M / T A \pm I / \Delta A$ & آزمايش & & \\
\hline$r \Delta F / \Delta \pm 1 Y / M F$ & كنترل & \multirow{2}{*}{ ييشآزمون } & \multirow{4}{*}{ قدرت يرش أفقي } \\
\hline rONA+EIF/\&E & أزمايش & & \\
\hline$r \Delta r / \lambda+ \pm 11 / r$. & 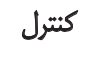 & \multirow{2}{*}{ يسآزمون } & \\
\hline TEYTH. $\pm I M / .$. & آزمايش & & \\
\hline $18 / r \Delta \pm . / 41$ & كثترل & \multirow{2}{*}{ وييشأزمون } & \multirow{4}{*}{$\begin{array}{c}\text { أرمون ايلينويز } \\
\text { (ثانيه) }\end{array}$} \\
\hline $1 \% 1 \cdot 9 \pm+19$ & آزمايش & & \\
\hline $18 / 79 \pm .141$ & كنترل & \multirow{2}{*}{ يسأَّمون } & \\
\hline $1 D / N+ \pm \cdot / 9 T$ & آزمايش & & \\
\hline IT/ENETHY & كنترل & \multirow{2}{*}{ ييشآزمون } & \multirow{4}{*}{ درصد هربى بلن } \\
\hline W/OAET/RE & آزرمايش & & \\
\hline$|Y M| \pm \varphi / \cdot \Lambda$ & كثترل & \multirow{2}{*}{ يس آزّمون } & \\
\hline $11 / \cdot 9 \pm 1 / 1 / 8$ & آزمايش & & \\
\hline
\end{tabular}

مجله بيومكانيك ورنش

تمرينات يليومتريك ميتواند باعث افزايش قدرت و هابكى شود.

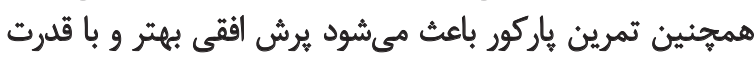

$$
\text { بيشترى انجام شود. }
$$

قدرت كانسنتريك و سفتى بالاي عضلات دومفصله يشت ران، كه

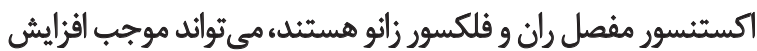

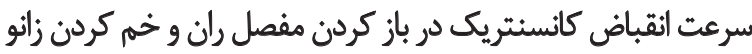

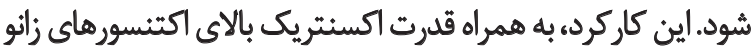

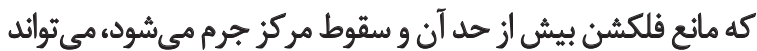

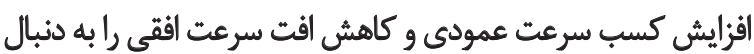

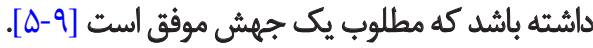

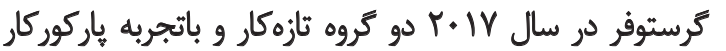

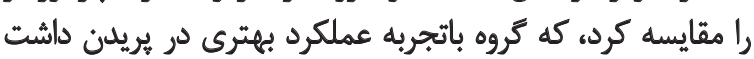

$$
\text { بخشيد (جداول شماره بر ب). }
$$

با توجه به اساس ورزش باركور يعنى يريدن مي توان با افزايش

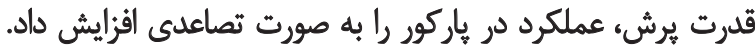

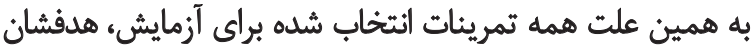
افزايش برش است.

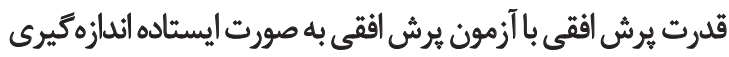

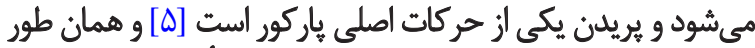

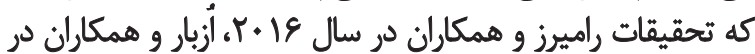

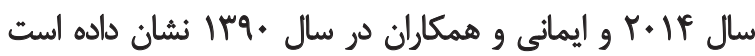


جدول ץ. مقايسه ميانكين متغيرهاي وابسته در مراحل بيش آزمون و بسآزمون در دو گروه كنترل و آزمايش (هر كروه • انفر)

\begin{tabular}{|c|c|c|c|c|c|c|}
\hline معنى سطالحي & df & مقدار تى & ميانكين 土انحراف استاندارد & كروه & زمان & متغيرها \\
\hline $.1 .01^{*}$ & 9 & $-1 / e^{2} u$ & 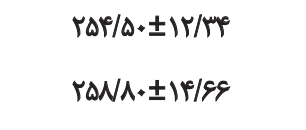 & كتثل & ييش أزمون & قدرت برش اققى \\
\hline$\cdot M+1$ & 9 & $+/ M+1$ & 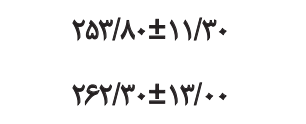 & كتئل & يس آلزمون & (سائتىمتر) \\
\hline $.1 \cdot 11{ }^{*}$ & 9 & $r / M E$ & $\begin{array}{l}|\& / T \Delta \pm| / \Delta \mid \\
\mid \% / \cdot 9 \pm \cdot / 9 .\end{array}$ & كنترل & ييش آز هون & \multirow{2}{*}{ آزمون ايلينويز (ثاثيه) } \\
\hline$\cdot / A r^{*} \cdot$ & 9 & $-+/ M T I$ & $\begin{array}{l}18 / \mathrm{Tq} \pm . / 41 \\
18 / V+ \pm \cdot / 9 T\end{array}$ & كنترل & يس آلزمون & \\
\hline $1 .+19^{\circ}$ & 9 & $r / T W$ & $\begin{array}{l}\text { W/EVET/M } \\
\text { W/QAEY/TE }\end{array}$ & كثترل & ييش آزمهن & \multirow[b]{2}{*}{ درصد جربى بلن } \\
\hline - /AVA & 9 & -.1101 & $\begin{array}{l}\mid T / N \pm+/ \cdot 1 \\
(1 / \cdot q \pm 1 / N\end{array}$ & كثترل & يس آآزهون & \\
\hline.$/ \pi$ & 9 & I/TM & 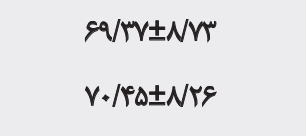 & كنترل & ييش أزمون & \multirow{2}{*}{ وزن بلن (كيلوكرم) } \\
\hline / IAFA & 9 &.$- / 9 T F$ & $\begin{array}{l}\text { Eq/SA } \pm N / q \\
\text { Eq/AY } \pm V / F A\end{array}$ & كتئرل & يس آزمون & \\
\hline . rar & 9 & $1 / 118$ & $\begin{array}{l}r M / \Delta Y \pm Y / \cdot r \\
r Y / \Delta T \pm 1 / F e\end{array}$ & كنترل & ييسّ آزمون & \multirow{2}{*}{ (كيلوكرم بر مثرمربع توده بدنى } \\
\hline$+18+1$ & 9 & $-\cdot / \Delta M Y$ & $\begin{array}{l}r r / g \Delta \pm 1 / q T \\
r T / T A \pm I / \Delta A\end{array}$ & كنترل & يس آلزمون & \\
\hline
\end{tabular}

جدول ٪. نتايج آزمون تى مستقل در مقايسه شاخصهاى كينماتيك زانو

\begin{tabular}{|c|c|c|c|c|}
\hline \multirow{2}{*}{ سطح معنى دارى } & \multirow{2}{*}{ مقدار تى } & \multicolumn{2}{|c|}{ مياتيكين|نحراق اسثاندارد } & \multirow{2}{*}{ 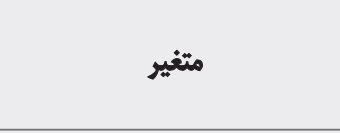 } \\
\hline & & يسأزمون & بيشآزمون & \\
\hline$\cdot 1+\cdot r^{\infty}$ & $r / A \Delta)^{\prime}$ & $q / q u \pm r / \cdot r$ & W/NEET/EA & افت ناوى (سانتىمتر) \\
\hline.$|+|^{*}$ & $-m / F i$ & $18 / 1 \pm E M$ & $M / T r \pm F / M$ & 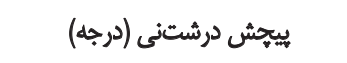 \\
\hline.$/ 11$ & $-8 / \pi$ & ID/RETM/RT & $|\Delta / 8 \Delta \pm r / T|$ & زاويه Q (درجه) \\
\hline.$/ 01 Y$ &.$/ \mathrm{rA}$ & IF/rTEte/RV & $\mid \varepsilon / r q \pm r / u$ & زاويه أتثرورثن (درجه) \\
\hline.$/ 79 \Delta$ & . /9Ar & $r q / + \pm r / R r$ & $m / T P \pm \varphi / p i$ & هرخش داخلى وخارجى ران (درجه) \\
\hline $.1 . p r$ & $\mid / N T$ & $N e q \pm r / . q$ & V/APEY/QY & هايير اكستششن زانو (درجه) \\
\hline
\end{tabular}


سمت است. اختلاف ظاهرى طول ياها در طول زمان بر اثر اجراى

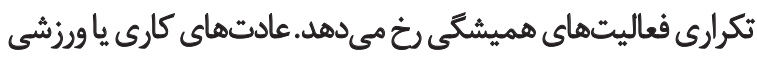

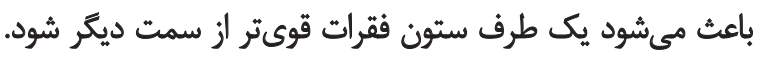

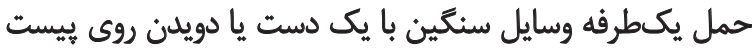

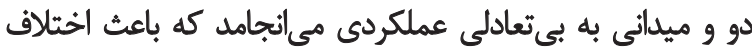

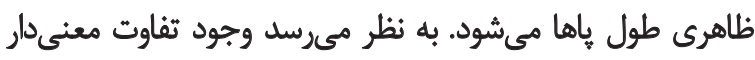

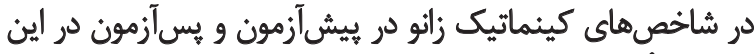

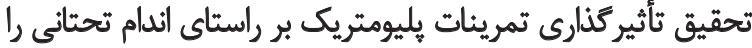

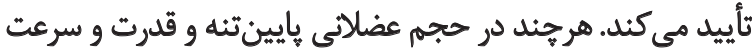

ورزشكاران در تحقيقات قبلى نتايج معنى دار كزارش شده استئ ونات

\section{نتيجلكيرىنهايي}

با توجه به مقايسه بيشآزمون و يسآزمون كروهها و با توجه به

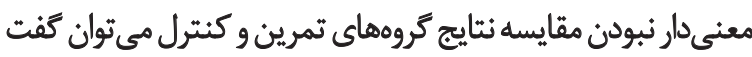

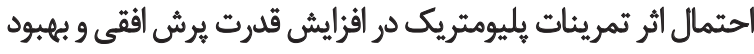

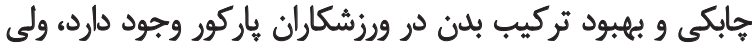

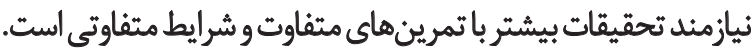

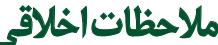

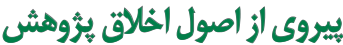

تمامى آزمودنىها داوطلبانه در اين يرؤهش شركث كردند و رونائ

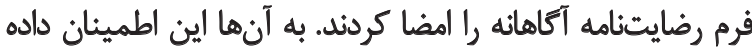

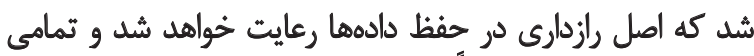

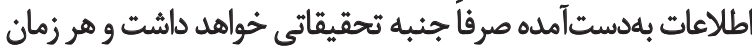

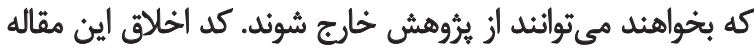

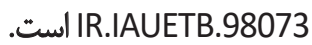

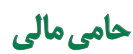

مقاله حاضر بركرفته از يك طرح يُروهشى در دانشكاه آزاد اسلامى ترئ

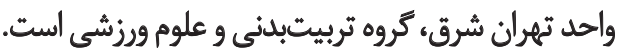

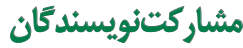

تمامى مراحل تنظيم مقاله به عهلده نويسنده الول بوده است وخاتم

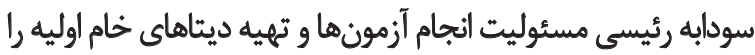

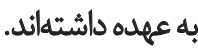
ت تعارض مناقع بنا به اظهار نويسندكان اين مقاله تعارض منافع ندارد.
و همجينين در اين تحقيق بيشنهاد شده است كه با كذشت زمان

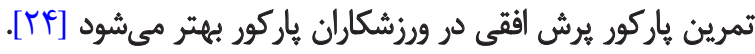

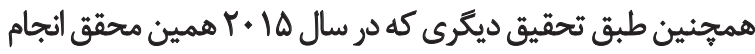

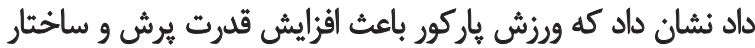

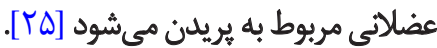

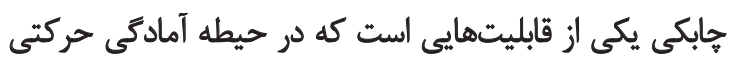

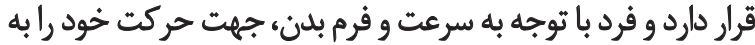

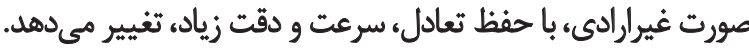

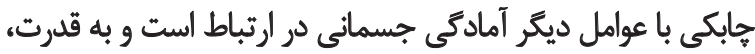

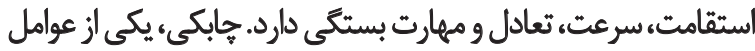

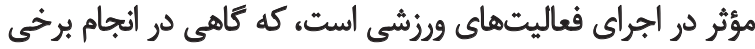

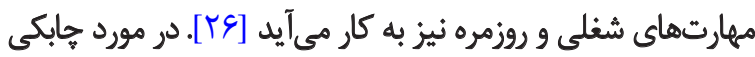

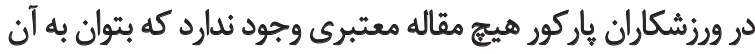

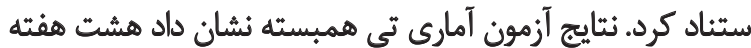

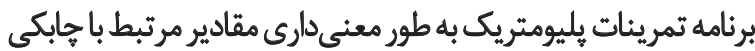

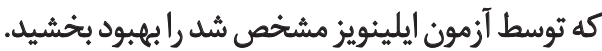
باتوجه به بهبود آزمون جابكى آزمودنىها در تروه تمرين، مقايسه

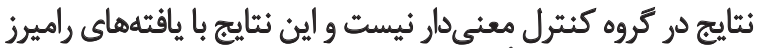

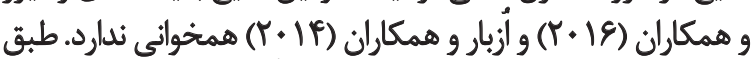

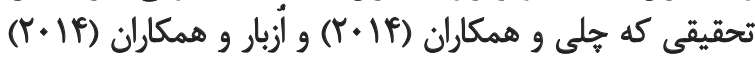

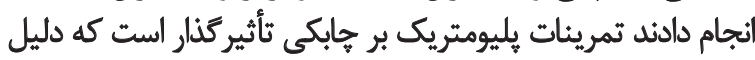

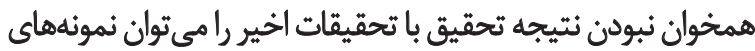

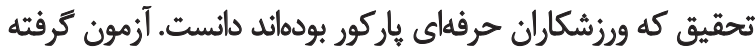

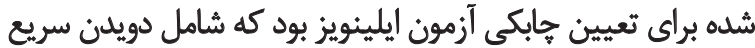

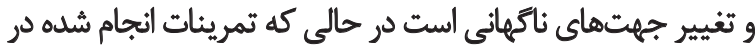

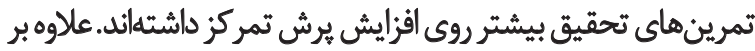

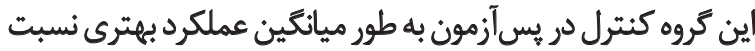

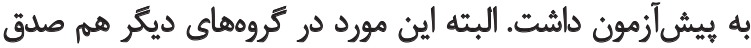

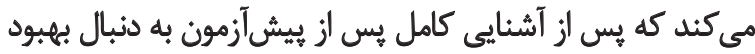
عملكرد خود بودهاند كه جزو تمرينات نبوده است آنائ

تركيب بلن نسبت جرم جربى و جربى بدن است. تركيبى از بدن

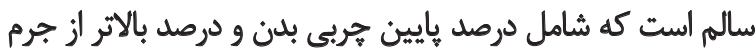

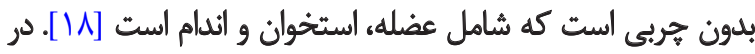

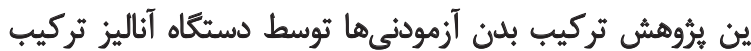

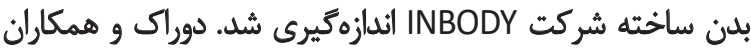

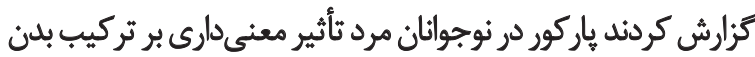

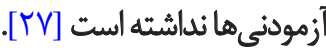

ولى در اين يُروهش نتايج آزمون آمارى تى همبسته نشان داد

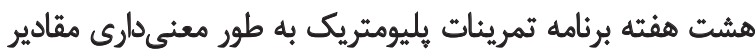

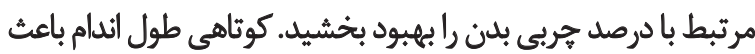

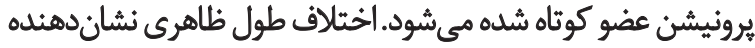

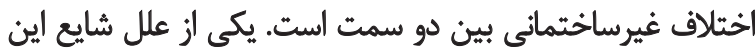

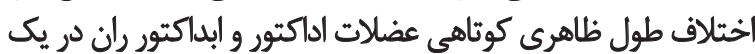




\section{References}

[1] Contributors W. Parkour [Internet]. Wikipedia: The Free Encyclopedia; 2020 [Cited 2020 May 24]. Available from: https://en.wikipedia.org/w/ index.php?title=Parkour\&oldid=957673945.

[2] Ramezanpour MR, Moghaddam A, Alizadeh M. [The effects of plyometric trainings on legs explosive power, velocity, agility and flexibility in taekwondo players (Persian)]. J Sport Biosci Rese. 2011; 1(1):63-71. https://www. sid.ir/en/journal/ViewPaper.aspx?ID=343367

[3] Hewett TE, Stroupe AL, Nance TA, Noyes FR. Plyometric training in female athletes: Decreased impact forces and increased hamstring torques. Am J Sports Med. 1996; 24(6):765-73. [DOI:10.1177/036354659602400611] [PMID]

[4] Svantesson U, Grimby G, Thomee R. Potentiation of concentric planta flexion torque following eccentric and isometric muscle actions. Acta Physiol Scand. 1994; 152(3):287-93. [DOI:10.1111/j.1748-1716.1994. tb09808.x] [PMID]

[5] Kidder JL. Parkour and the city: Risk, masculinity, and meaning in a postmodern sport. New Brunswick: Rutgers University Press; 2017. [DOI:10.36019/9780813571980]

[6] Mojtaba I. [The effect of 4 weeks resistance and polymetric training programs on the performance of male soccer players aged 15 to 17 (Persian)] [MSc. thesis]. Kermanshah: Razi University; 2011

[7] Ozbar N, Ates S, Agopyan A. The effect of 8-week plyometric training on le power, jump and sprint performance in female soccer players. J Strength Cond Res. 2014; 28(10):2888-94. [DOI:10.1519/JSC.0000000000000541] [PMID]

[8] Ramírez-Campillo R, González-Jurado JA, Martínez C, Nakamura FY, Peñailillo L, Meylan CMP, et al. Effects of plyometric training and creatine supplementation on maximal-intensity exercise and endurance in female soccer players. J Sci Med Sport. 2016; 19(8):682-7. [DOI:10.1016/j. jsams.2015.10.005] [PMID]

[9] Panoutsakopoulos V, Papaiakovou GI, Katsikas FS, Kollias IA. 3D Biomechanical analysis of the preparation of the long jump take-off. New Stud Athl. 2010; 25(1):55-68. https://www.semanticscholar.org/paper/

[10] Toumi H, Best TM, Martin A, Poumarat G. Muscle plasticity after weight and combined (weight + jump) training. Med Sci Sports Exerc. 2004 36(9):1580-8. [DOI:10.1249/01.mss.0000139896.73157.21] [PMID]

[11] Wilson JM, Fitschen PJ, Campbell B, Wilson GJ, Zanchi N, Taylor L, et al. International Society of Sports Nutrition position stand: Beta-hydroxy-beta-methylbutyrate (HMB). J Int Soc Sports Nutr. 2013; 10(1):6 [DOI:10.1186/1550-2783-10-6] [PMID] [PMCID]

[12] Kyröläinen H, Avela J, McBride JM, Koskinen S, Andersen JL, Sipilä S, et al. Effects of power training on mechanical efficiency in jumping. Eur J Appl Physiol 2004; 91(2-3):155-9. [DOI:10.1007/s00421-003-0934-z] [PMID]

[13] Shambaugh JP, Klein A, Herbert JH. Structural measures as predictors of injury basketball players. Med Sci Sports Exerc. 1991; 23(5):522-7. [DOI:10.1249/00005768-199105000-00003] [PMID]

[14] Marriott BM, Grumstrup-Scott J. Body composition and physical performance: Applications for the military services. Washington, D.C.: National Academies Press; 1992. https://books.google.com/books/about/Body Composition_and_Physical_Performanc.html?id=h1krAAAAYAAJ

[15] Wood R. Standing Long Jump Test. Topend Sports Website; 2008. [https://www.topendsports.com/testing/tests/longjump.htm Accessed $12 / 18 / 2020]$
[16] Wood R. Illinois Agility Test (IAT). Topend Sports Website; 2008. https://www.topendsports.com/testing/tests/illinois.htm, Accessed $12 / 18 / 2020$

[17] Leetun DT, Ireland ML, Willson JD, Ballantyne BT, DAVIS IM. Core stability measures as risk factors for lower extremityinjury in athletes. Med Sci Sports Exerc. 2004; 36(6):926-34. [DOI:10.1249/01.MSS.0000128145.75199.C3] [PMID]

[18] Heerspink FOL, Hoogeslag RA, Diercks RL, van Eerden PJ, van den AkkerScheek I, van Raay JJ. Clinical and radiological outcome of conservative vs. Surgical treatment of atraumatic degenerative rotator cuff rupture: Design of a randomized controlled trial. BMC Musculoskelet Disord. 2011; 12:25 [DOI:10.1186/1471-2474-12-25] [PMID] [PMCID]

[19] Daneshmandi H, Alizadeh MH, Shadman B. [The effect of a training program on the position of the scapular bone (Persian)]. Scientific Information Database. 2007; 4(11):93-107. https://www.sid.ir/fa/journal/ViewPaper. aspx?ID=63004

[20] Beaudreuil J, Bardin T, Orcel P, Goutallier D. Natural history or outcome with conservative treatment of degenerative rotator cuff tears. Joint Bone Spine. 2007; 74(6):527. [DOI:10.1249/10.1016/j.jbspin.2007.07.009] [PMID]

[21] Shoja Aldin SSAD, Sadeghi H, Bayat Tork M. [The relationship between trunk muscle strength and anthropometric characteristics with the Lumbar pain in athletes with lordosis (Persian)]. J Mov Sci Sport. 2009; 6(12):23-33. https://www.sid.ir/en/journal/ViewPaper.aspx?id=131531

[22] Alijani E. Exercise science. Tehran: Hatmi Publication; 2018. https://behtarinketab.com/practicing-science-alijani

[23] Haley A. 3 Unbreakable plyometric training rules [Internet]. 2017 [Updated 15 August 2017]. Available from: https://www.stack.com/a/ how-often-should-you-perform-plyos

[24] Grosprêtre S, Ufland P, Jecker D. The adaptation to standing long jump distance in parkour is performed by the modulation of specific variables prior and during take-off. Mov Sport Sci Motricité. 2018; (100):27-37. [DOI:10.1051/sm/2017022]

[25] Grosprêtre S, Lepers R. Performance characteristics of Parkour practitioners: Who are the traceurs?. Eur J Sport Sci. 2016; 16(5):526-35. [DOI:10.108 0/17461391.2015.1060263] [PMID]

[26] Contributors W. Agility [Internet]. Wikipedia: The Free Encyclopedia; 2020 [Cited 2020 May 24]. Available from: https://en.wikipedia.org/w/ index.php?title=Agility\&oldid=950271129.

[27] Dvorak M, Eves N, Bunc V, Balas J. Effects of parkour training on healthrelated physical fitness in male adolescents. Open Sports Sci J. 2017, 10(1):132-40. [DOI:10.2174/1875399X01710010132] 